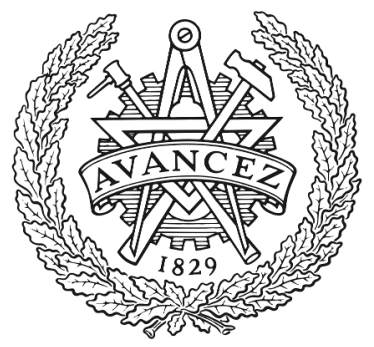

CHALMERS

UNIVERSITY OF TECHNOLOGY

\title{
Innovation for Low-Rise Construction in the Urban Tropics: Utilization of Structural Bamboo for Cost-Efficient Housing
}

Downloaded from: https://research.chalmers.se, 2023-04-26 14:57 UTC

Citation for the original published paper (version of record):

Salzer, C., Camarasa, C. (2015). Innovation for Low-Rise Construction in the Urban Tropics:

Utilization of Structural Bamboo for

Cost-Efficient Housing. 8th Conference of the International Forum on Urbanism (IFoU).

http://dx.doi.org/10.3390/ifou-e012

N.B. When citing this work, cite the original published paper. 


\title{
True Smart and Green Gity? \\ 8th Conference of the International Forumon Utbarism
}

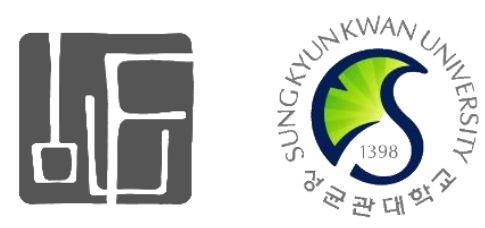

Conference Proceedings Paper

\section{Innovation for Low-Rise Construction in the Urban Tropics: Utilization of Structural Bamboo for Cost-Efficient Housing}

\author{
Corinna Salzer* ${ }^{1}$, Clara Camarasa ${ }^{1}$ \\ ${ }^{1}$ Chalmers University of Technology/ SE-412 96, Gothenburg, Sweden \\ * Author to whom correspondence should be addressed; \\ E-Mail: salzer@chalmers.se, Tel.: +41 786259 048;
}

Received: / Accepted: / Published:

\begin{abstract}
This paper deals with a cost-efficient construction technology using load bearing bamboo for urban low-rise housing in tropical Asia-Pacific. The potential of the technology to be applied at larger scale is discussed at the example of the Philippines as pilot country for its application. The assessment of alternative construction methods such as this one is motivated by a tremendous need for more affordable, sustainable and resilient housing around the globe. The urban poor, being the most underserved group in need of housing, often cannot afford conventional building technologies offered by the formal industry. Using locally available bamboo as structural component within the introduced standardized and quality controlled construction method is an entry point to provide performing and safe housing at lower cost. The paper highlights, however, that cost-efficiency and technical performance are not the only requirements for innovations to succeed on a market, especially due to the complex challenge of urban poor housing. Through learnings from the construction of 50 houses in the Philippines and interviews with various stakeholders along the value chain of the technology, barriers and opportunities for a scale-up are retrieved. For this paper, a conflated none-exhaustive overview of the identified aspects is documented. It was found that both barriers and opportunities directly linked to this technology are closely tied to a complex local value chain which ranges from upstream supply of raw material to downstream customer acceptance. The pilot application has shown further, that participatory product development reduces the acceptance barrier significantly by directly addressing the needs of low income customers. Material and skills availability, enabling policies and approval by legal entities as well as sustainability in supply of the organic raw material play important roles too. This complex set of interlinked aspects needs to be addressed according to targets in implementation-pace, and -scale as well as its intended social value creation. While multi-stakeholder participation is required for a successful up-scaling, a facilitating social enterprise, providing knowledge and services around the technology, can guide through the up-scaling.
\end{abstract}

Keywords: Urban Poor Housing / Building Technology / Bamboo / Innovation / Barriers and Opportunities / Asia-Pacific / Sustainability 


\section{Introduction}

The scope of this paper is to introduce a technology innovation for low-rise tropical construction and to highlight relevant barriers and opportunities for its application at larger scale. In the introduction chapter, the need and potential for an innovation in the sector of affordable housing is described. In the method chapter, the approach of retrieving the barriers and opportunities is described, which are then stated and discussed in the result and conclusion chapters in an abbreviated manner.

\subsection{Need for cost-efficient, sustainable and resilient housing}

Approximately 30 percent of the urban population in Asia-Pacific, which accounts for 570 Million people, lives in houses declared as none-adequate. Adequacy refers to a shelter providing safety and privacy, allowing health and well-being as well as access to utilities, public services, and being located in reach of sources for income. [1]. The aspect of safety, among others, requires structural performance of houses. Conventional construction technologies are not affordable for most urban low-income groups in Asia-Pacific. Therefore substandard practices are commonly applied in order to fit costs to the available financial means, which can cause fatal failures for example during earthquakes [2]. Alternatively people remain in temporary houses with little to no capacity to provide safety. Inhabitants living in substandard conventional or temporary houses are vulnerable during extreme impacts such as earthquakes, typhoons or floods. As one of the effects of climate change such extreme impacts are likely to occur more frequent. The Philippines, as pilot country of the construction method, belongs to the ten most affected countries on earth by Climate Change [3]. Community organizations such as the Homeless People`s Federation of the Philippines [4] make an effort to organize urban poor communities in order to receive a formal status in society through empowerment, land titles, housing finance and adequate, safe and resilient housing. With the existing lack of adequate housing and the rapid pace of urbanization, the need for cost-efficient, sustainable and resilient housing continuously increases [5].

\subsection{The material bamboo and its current utilization at the example of the Philippines}

The utilization of bamboo for construction of rural houses has a long tradition in the Philippines [6]. An abundant availability makes it an affordable raw material. Traditional forms of construction require that farmers living nearby the bamboo source frequently maintain parts of their houses. Due to simple connection methods, which underutilize the potential of the raw material, statistical information of the Philippine Government reveal that inhabitants living in those houses are vulnerable especially during typhoons [7]. Further, skills and knowledge for maintenance and replacements are diminishing in the last decades. People moving to suburban and urban areas often prefer to live in concrete or steel houses, which are considered more modern and safe. Traditional, none-standardized bamboo construction methods were never enhanced for a modern, resilient urban context. As per today an application as load bearing material remains therefore only in rural areas. While bamboo is still a part of the daily life of many people, a majority its users belong to low income groups. Urban poor settlers adapted the affordable material for none-load-bearing applications such as windows, fences, and temporary wall-claddings in informal settlements.

\subsection{A bamboo based construction technology for the urban tropics}

Urban building technologies need to be reliable, durable and in compliance with rules and regulations such as [8] or [9] in the case of the Philippines. Motivated by an availability-perspective, the considered bamboo-based technology shows that a technically more advanced use of local bamboo can bring about system change towards a more self-reliant and cost-efficient housing strategy in compliance with the existing policies. The presented technology is the result of three years technical development, leading to a structurally performing, reliable and durable construction method. The technology is based on gathering of traditional local knowledge, a South-South 
knowledge exchange with Latin America, testing of Philippine bamboo, and modern engineering.

For more details on the construction technology is referred to [10,11].

\section{Method}

The approach of retrieving relevant barriers and opportunities for a large scale application of the construction innovation contains the following two steps:

2.1. Status Quo of the Technology Application: An abbreviated description about the technology innovation is given and the status quo of its application is described.

2.2. Insights on Barriers and Opportunities from Stakeholder View: Key stakeholder groups involved in a scale-up are identified by mapping them along the existing value chain of the technology. Through stakeholder interviews, an overview about relevant barriers and opportunities are gathered. Key aspects are stated and categorized in this paper in a none-exhaustive manner. All interviewed persons had an in-depth understanding of the application country, the Philippines, and have either a profession in the construction field, work in the social housing sector or belong to a potential customer group. Half of the interviewees have been directly linked to the technology development or its pilot application, while the other half looked at it from the outside.

\section{Results and Discussion}

This chapter is divided in the subchapters Status Quo of the Technology Application and Insights on Barriers and Opportunities from Stakeholder View.

\subsection{Status Quo of the Technology Application}

The building technology is a bamboo-based frame construction method. Bamboo shear walls are prefabricated using vertical bamboo studs. Tested raw materials and connections ensure a durable and reliable load transfer and allow a structural design according to the intended resistance of the system. For this process, the standards $[10,12,13,14]$ are applied under incorporation of the test results stated in [15]. The load bearing system is covered by plaster. The construction system is displayed in below picture series:
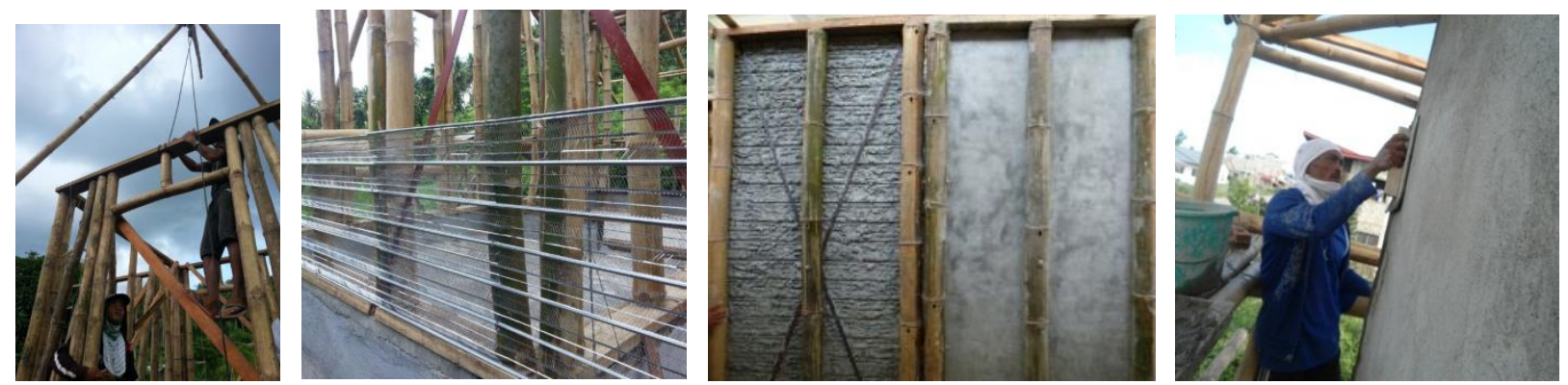

Pictures 1-4. Construction System using prefabricated bamboo frames and mortar coating

As per April 2015, the construction technology has been applied by the social enterprise Base [11] for 50 houses and in two of the three regions of the Philippines: Luzon and Visayas. Both, one and two story houses, single detached and duplex houses have been built. The houses were either sold or provided for victims of disasters. A small share of houses was used for demonstration or test purposes. A positive market acceptance was obtained for 20 units that were sold to low income groups by the community organization [4], which is partnering with Base Builds in the city of Iloilo. A significant scale-up and an expansion to other markets are deemed possible. 

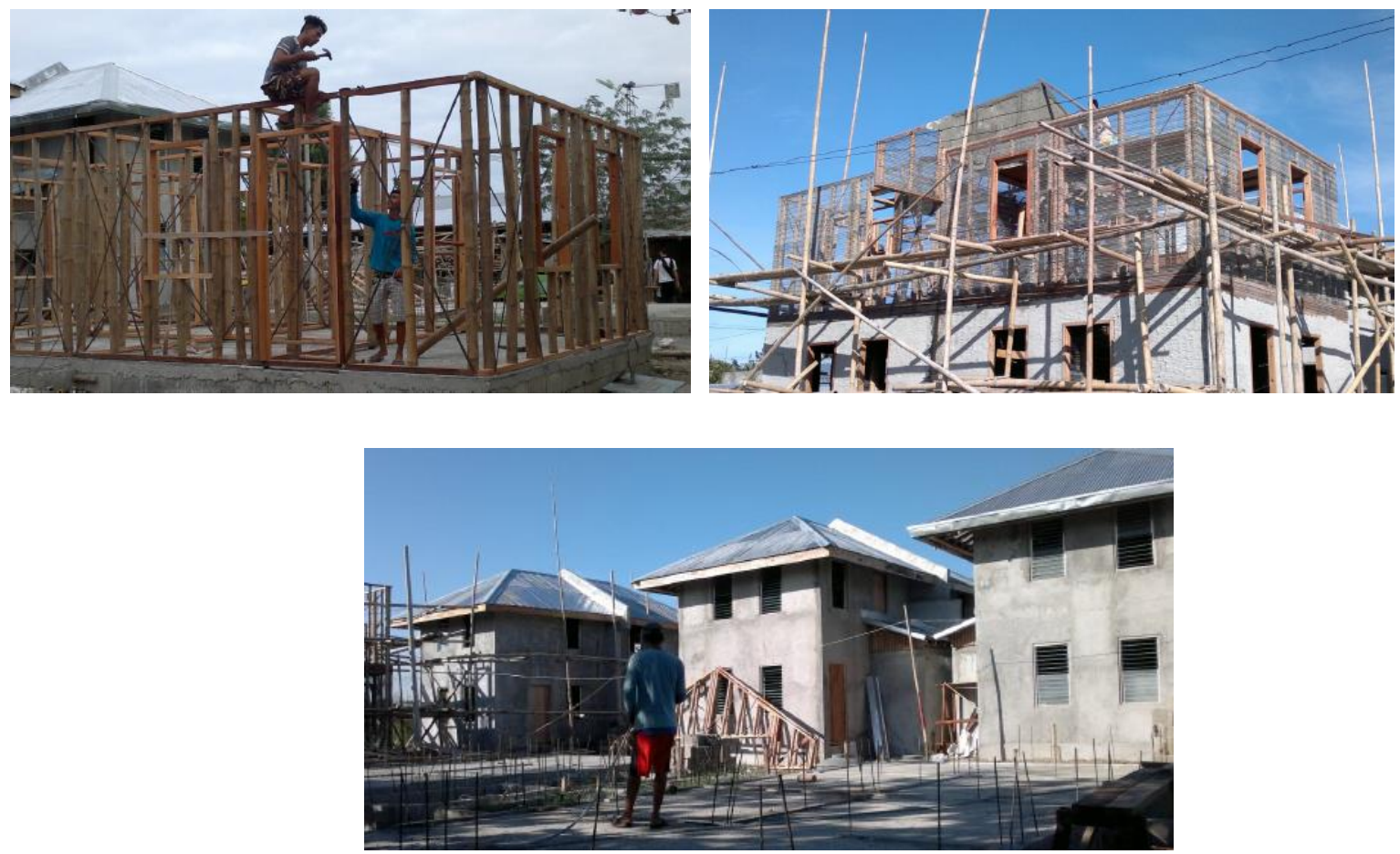

Pictures 5-7. Construction of ten two-story duplex houses, Iloilo City, March 2015 [11]

\subsection{Insights on Barriers and Opportunities from Stakeholder View}

In total, sixteen stakeholder interviews with a minimum of two members from each stakeholder group were conducted. The stakeholders have been grouped into six categories: Policy Makers / Customer Groups / Construction Sector, Housing Component or Service Providers / Technical Professionals and Scientists (Engineers, Architects, Material Scientist, etc.) / Raw Material Suppliers / and Facilitators (International Organizations, etc.).

Given the complexity of the field Affordable Housing, two categories of barriers and opportunities were distinguished:

A. Barriers and Chances within the wider conceptual framework of affordable housing, and

B. Barriers and Chances directly related to the value chain of the building technology

Major interdependent aspects of the wider conceptual framework of housing are among others land tenure, housing finance, governance and policies in urban development, empowerment and organization of informal communities as customers, income generation for marginalized groups as well as basic services and infrastructure of settlements. Consequently, stakeholders dealing with or being affected by these overarching wider aspects, such as policy makers, International Organizations, or low income groups have stressed these aspects the most during the interviews. It is acknowledged, that the aspects of the conceptual framework have to be addressed for a system change at scale. However, it is further recognized that an individual provider of an innovation in the construction sector does not likely change such barriers. An adjustment to it or, at best, influence of it can be achieved by long term multi-stakeholder dialogues and high-level advocacy. Barriers and opportunities along the value chain of the bamboo-based technology, on the other hand, can be shaped or even controlled by the service provider. For this paper a consolidated summary of nine relevant barriers and opportunities were derived, which are described below in an abbreviated manner:

1. Policies for building technologies

Regulations can facilitate the scale-up of a performing technology on the market. Currently, housing for low income groups is often exempted from rules and regulations. Further, 
alternative building technologies are not covered by building codes. The lack of minimum structural performance requirements, make substandard technical practices likely and might slow down the spread of a performing technology.

2. Customer Acceptance

Housing is a once in a life-time investment for families, therefore trust into the building technology is highly relevant for success. The introduction of a new construction system has to gain this trust for an effective scale-up.

3. Cost advantage

Lower construction costs are a major incentive for stakeholders and make houses affordable for more people in need. Cost advantages are therefore an important entry point for system change, however, not the only requirement for the innovation to succeed on the social housing market.

4. Business model

Besides economic feasibility, a socially-inclusive and ecological enterprise model has to balance the needs of suppliers and customers and ensure overall affordability and feasibility. During stakeholder interviews it was acknowledged, that the social enterprise [5], advocating for the application of the technology, has such a business model as substantial part of their mission and vision.

5. Sustainable Cultivation Practices

Fast growing bamboos allow a high yield. The aspect of sustainable growth and harvesting becomes however crucial for long term sustainable supply with given ecologic reproducibility limits and a needed minimum quality for the poles. The factors (1) pace of scale-up and (2) absolute scale intended are crucial for a strategy definition.

6. Logistics of a Supply Chain

Bamboo is neither a fix-priced, nor a standardized forest product in the Philippines. Therefore the availability for the market and a demand-supply balance are critical. Logistical efforts with lacking infrastructures are increased.

7. Technical Development

Investing into a residential home is a long term commitment for low income customers. A new technology might cause customers or loan providers to hesitate. A comprehensive technical development, as it is given for the introduced technology, is the basis for an up-scaling to ensure reliability and durability. During interviews with stakeholders involved in the technology development, this solid basis has resulted in solid trust into the technology.

8. Capacity Building

Capacity building for quality control in supply as well as construction is a requirement. This involves all levels of stakeholders, from skilled and low-skilled workers to academe and is has to be built-up for an application of the technology at large scale.

9. After Sales Services

Services for Maintenance of Houses, Incremental Expansion and Upgrading along with Societal Development are needed as customer post-occupation service and for ensuring durable performance.

Barriers mentioned above can be also interpreted as opportunities, once there are corresponding strategies for addressing them. The interviews revealed that a comprehensive technical development as stated under bullet point seven and an inclusive business model as stated under bullet point four are given for the considered technology. Further, opportunities for scaling-up the application are for example the legal approval of the building technology for a nationwide application, the inclusion of low income customers in the technical development as a pathway to acceptance, capacity building along the value chain, and continuous process optimization and quality control. Comprehensive strategies have to be developed covering all identified barriers. 


\section{Discussion and Conclusions}

A cost-efficient building technology using bamboo for the tropical residential housing market in Asia has been introduced with the Philippines being the pilot country for its application. Due to a cost advantage compared to conventional solutions, one intended customer group are low income settlers who are in urgent need for more adequate and resilient housing and wish to formalize their status in society. The pilot market Philippines represents a challenging environment for a building technology, since extreme impacts are demanding high technical performance, while in the same hand the affordability level of low income groups is low. The Philippines application is therefore seen as pathfinder for an expansion in Asia-Pacific. For it to be successfully scaled, both in the Philippines and further countries of Asia-Pacific, a complex set of interlinked aspects has to be tackled.

For the classification or barriers it was distinguished between (1) aspects of a wider conceptual framework surrounding housing provision and (2) aspects directly linked to the value chain of the technology. Since the technology has to adapt to the conceptual framework, rather than influence it, aspects in this category are not in the focus of this paper. Instead, insights on the direct technology related aspects are given, which resulted in nine interlinked key barriers: Policies / Customer Acceptance / Cost advantage / Business model / Sustainable Cultivation Practices / Logistics of a Supply Chain / Technical Development / Capacity Building / After Sales Services.

Given a tremendous, constantly growing need for sustainable and resilient housing in Asia-Pacific, the presented bamboo-based building technology holds a promising potential for social, ecologic and economic impact creation. The mentioned barriers have to be addressed or are already on the way to be addressed by the current technology providers in order to scale-up the technology application in the coming years. Multi-stakeholder participation is required for a successful upscaling, which can be guided by the technology provider. Strategies for addressing the barriers need to be developed according to targets in implementation-pace, and -scale as well as the intended degree of social impact.

\section{Acknowledgments}

The technology presented in this conference was developed and is applied in a larger program on sustainable and resilient housing initiated by the Hilti Foundation (HF). Acknowledgement is given to BASE Builds Pte. Ltd. and the social enterprise BASE Bahay Inc. (Philippines) which are initiatives of Hilti Foundation. For further information, it is referred to www.base-builds.com. The pictures displayed in the presentation are from a collaboration project of BASE and the Homeless People`s Federation of the Philippines (HPFPI). HPFPI is acknowledged as community organization with comprehensive understanding of housing provision for low income groups.

\section{Conflict of Interest}

The authors declare no conflict of interest.

\section{References}

1. UN Habitat (2010), The State of Asian Cities Report 2010/2011, Fukuoka, Japan

2. ASEP (2013). Post-disaster damage assessment after Bohol earthquake in 2013. Association of Structural Engineers of the Philippines (ASEP), Manila

3. IPCC (2014), Fifth Assessment Report Climate Change 2014: Impacts, Adaptation, and Vulnerability, International Panel on Climate Change

4. Homeless People`s Federation of the Philippines (2015), http://www.hpfpi.org/ 
5. National Housing Authority of the Philippines (2015), http://nha.gov.ph/

6. FPRDI (2002). Utilization, Collection and Trade of Tropical Non-Wood Forest Products in the Philippines. Los Banos, Forest Products Research and Development Insitute

7. Cinco T. (2013), Sever Wind Impacts and Destruction of Houses after Typhoon Hayian, Philippine Atmospheric, Geophysical, and Astronomical Services Administration (Pagasa)

8. ASEP (1992). National Structural Code of the Philippines, Volume 1. Association of Structural Engineers of the Philippines (ASEP), Manila

9. HTDO (2013), Manual on Accreditation of Innovative Technologies for Housing, Housing Technology Development Office Philippines (HTDO), Quezon City

10. AIS (2010). NSR-10: Section E: One and two-story structures from Bahareque; Section E: Bamboo Space Structures, Colombian Association of Earthquake Engineers, Bogota, 2009.

11. Base Builds Inc., http://www.base-builds.com/

12. ISO (2004a). ISO 22156: Bamboo - Structural design. International Standards Organization, Geneva

13. ISO (2004b). ISO 22157-1: Bamboo - Determination of physical and mechanical properties - Part I: Requirements. International Standards Organization, Geneva

14. ISO (2004c). ISO 22157-2: Bamboo - Determination of physical and mechanical properties - Part II: Laboratory manual. International Standards Organization, Geneva

15. Base Builds (2013). Test Report: Mechanical Properties, Connection and Shear Wall Tests of Bambusa Bluemeana, Internal Research Document, Base Builds PTE LTD, Singapore

(C) 2015 by the authors; licensee MDPI and IFoU, This article is an open access article distributed under the terms and conditions of the Creative Commons Attribution license. 